STRUCTURAL BIOLOGY COMMUNICATIONS

ISSN 2053-230X

Received 16 November 2017

Accepted 16 November 2017

Keywords: myelin-gene regulation; MRF; DNAbinding domain; trimeric transcription factor;

X-ray crystallography; corrigendum

\section{DNA-binding domain of myelin-gene regulatory factor: purification, crystallization and X-ray analysis. Corrigendum}

\author{
WenYu Wu, ${ }^{a, b *}$ Xiangkai Zhen ${ }^{a, b}$ and Ning Shi ${ }^{a, b *}$
}

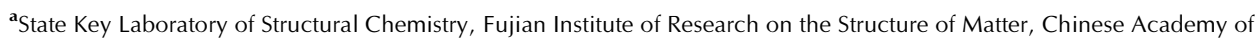
Sciences, 155 Yangqiao Road West, Fuzhou, Fujian 350002, People's Republic of China, and 'buniversity of Chinese Academy of Sciences, No. 19 Yuquan Road, Beijing, Beijng, 100049, People's Republic of China. *Correspondence e-mail: wuwenyu@fjirsm.ac.cn, shining@fjirsm.ac.cn

An extra affiliation is added for the authors of the article by Wu et al. [(2017), Acta Cryst. F73, 393-397].

In the article by Wu et al. (2017) all the authors should have the following additional affiliation: University of Chinese Academy of Sciences, No. 19 Yuquan Road, Beijing, Beijng 100049, People's Republic of China.

\section{References}

Wu, W., Zhen, X. \& Shi, N. (2017). Acta Cryst. F73, 393-397.

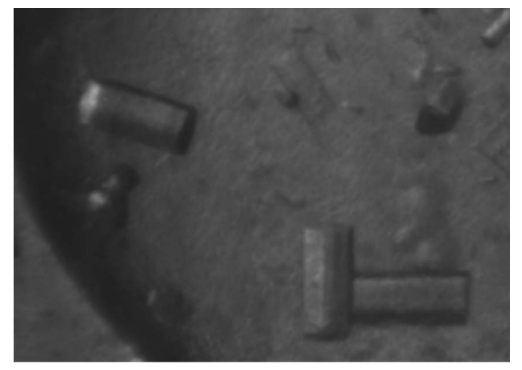

